\title{
Fibrodysplasia Ossificans Progressiva in Three Filipino Children
}

\author{
Maria Melanie Liberty B. Alcausin, ${ }^{1,2}$ Melissa Mae P. Baluyot, ${ }^{1}$ Eileen M. Shore, $, 3,5,6$ and Frederick S. Kaplan ${ }^{3,4,6}$ \\ ${ }^{1}$ Institute of Human Genetics, National Institutes of Health, University of the Philippines Manila \\ ${ }^{2}$ Department of Pediatrics, Philippine General Hospital, Manila, Philippines \\ The Departments of Orthopaedic Surgery, ${ }^{3}$ Medicine, ${ }^{4}$ and Genetics, ${ }^{5}$ and Center for Research in FOP and Related Disorders, ${ }^{6}$ \\ the Perelman School of Medicine, The University of Pennsylvania, Philadelphia, Pennsylvania, USA
}

\begin{abstract}
Fibrodysplasia ossificans progressiva (FOP) is a debilitating, rare, autosomal dominant disorder of connective tissue characterized by malformed great toes and by progressive endochondral ossification of extra-skeletal sites (e.g., muscles, tendons, fascia) triggered by trauma, soft tissue injury, muscle fatigue, or viral infections. We present three children affected with FOP with this classic clinical presentation, the first reported cases in the Philippines, thus extending the range of classic FOP to new geographic and ethnic locations. Two of the affected children are siblings who have the common ACVR1 R206H mutation associated with classic FOP; this mutation was not found in their parents who are phenotypically unaffected, providing evidence of germline mosaicism in FOP. To our knowledge, this is the first family with genetic testing done showing presence of the classic mutation in affected siblings not seen in the unaffected parents.
\end{abstract}

Key Words: fibrodysplasia ossificans progressiva, germline mosaicism, Filipinos, ACVR1

\section{INTRODUCTION}

Paper presented as poster at the $6^{\text {th }}$ International Conference on Birth Defects and Disabilities in the Developing World: Embedding Birth Defects in the Continuum of Care, November 10-13, 2013, Mactan, Cebu, Philippines.

Corresponding author: Maria Melanie Liberty B. Alcausin, MD Institute of Human Genetics National Institutes of Health

University of the Philippines Manila

Pedro Gil St., Ermita, Manila 1000, Philippines

Email: mbalcausin@up.edu.ph
Fibrodysplasia ossificans progressiva (FOP; MIM\# 135100) is a rare autosomal dominant disorder of connective tissue characterized by malformed great toes and by progressive heterotopic endochondral ossification in characteristic anatomic patterns. ${ }^{1,2}$

The worldwide prevalence of FOP is approximately 1 in 2 million, without racial, ethnic, gender, or geographic predilection. ${ }^{3}$ During the first decade of life, episodic soft tissue swellings, commonly referred to as flare-ups, usually occur. Most of these flare-ups transform soft connective tissues into mature heterotopic bone and produce an "armament-like encasement of bone with permanent immobility." Intramuscular immunizations, bumps, bruises, falls, or influenza-like viral illnesses can trigger painful new flare-ups of FOP contributing to progressive immobility. ${ }^{4,5}$

Despite these clinically unique diagnostic criteria, most patients with FOP are misdiagnosed by clinicians because of lack of awareness of this condition. ${ }^{6,7}$ Patients are sometimes mistaken to have cancer and subsequently undergo dangerous and unnecessary diagnostic procedures such as incisional and excisional biopsies and even amputations that can aggravate the patient's condition, trigger explosive new bone formation and lead to lifelong disability. ${ }^{6,7}$

An increased awareness of physicians and other health care providers, especially those involved in primary care, would lead to the early recognition, appropriate management and timely referral to subspecialists. Neonatologists, general 
pediatricians, orthopedic surgeons, and rheumatologists, with early referral, will accordingly be aided in the provision of an early diagnosis and appropriate management involving avoidance of inciting events. ${ }^{8}$

With the objective of increasing awareness for earlier recognition of this rare condition, we present this case series of three Filipino children with clinically and genetically confirmed FOP.

\section{PATIENT 1}

Patient 1 was seven years old when first seen by our Genetics Service. She presented with a limited mouth opening and multiple bony masses on various parts of the body. She is the third child of a healthy nonconsanguineous Filipino couple. She had unremarkable prenatal and perinatal history but was noted to have short and laterally deviated great toes at birth. At one year of age, she developed soft tissue swellings of her occiput and neck which eventually subsided but matured into multiple hard masses that resulted in restriction of neck movement. At two years of age, due to persistence of the masses, surgery was advised but this was not performed due to financial constraints. She later developed additional soft tissue swellings that eventually transformed to hard masses on her left shoulder, anterior chest, right knee and left axillary area. Some of these swellings developed after minor blunt trauma but most occurred without any known trauma. At seven years of age, she developed bony masses on her chin and later developed a severely restricted mouth opening which led to the subsequent consultation at our clinic. She attended regular school. Her developmental milestones were normal for her age. No other family member had similar symptoms.

On physical examination, patient 1 was at the $25^{\text {th }}$ percentile for height and weight. She had multiple bony masses on her occiput and chin with limited mouth opening of less than three centimeters. More hard masses were noted on the left clavicle, both axillae and left posterior thorax. A continuous sheet of bone spanned the anterior thorax from the left axilla to the right clavicle. There were other bony lumps on right knee and malleoli with short, medially deviated great toes (Figure 1). She had severe limitation of range of motion of the neck, shoulders and trunk. There were full range of motion of the elbows, wrists, hips, knees and ankles.

Her skeletal survey revealed osteochondromas of the distal femurs and proximal tibias, fusion of the facet joints of most cervical vertebrae, extensive bony outgrowth from the sternal area spanning the left upper hemithorax extending to the supraclavicular area, bilateral monophalangism of the great toes, short first metatarpals, and severe scoliosis (Figure 2). Computed tomography of the chest showed extensive heterotopic ossification (Figure 3).

Based on these findings, a clinical diagnosis of FOP was made. FOP mutation analysis was performed and revealed the recurrent ACVR1/ALK2 c.617G>A; R206H mutation that is associated with classic FOP. Neither of her parents had the mutation. Extensive counseling on FOP was provided to the family.

\section{PATIENTS 2 AND 3}

Patients 2 and 3 are brothers who were 12 years and nine years old, respectively, when they were first seen by our Genetics Service. They are the children of a nonconsanguineous Filipino couple and have two unaffected half-sisters from their mother's previous marriage. Both had unremarkable pre-natal and birth histories. There were no concerns with development. Patient 3 was a Grade 4 student in a regular school, while patient 2 finished fifth grade but refused to continue his schooling due to his condition.
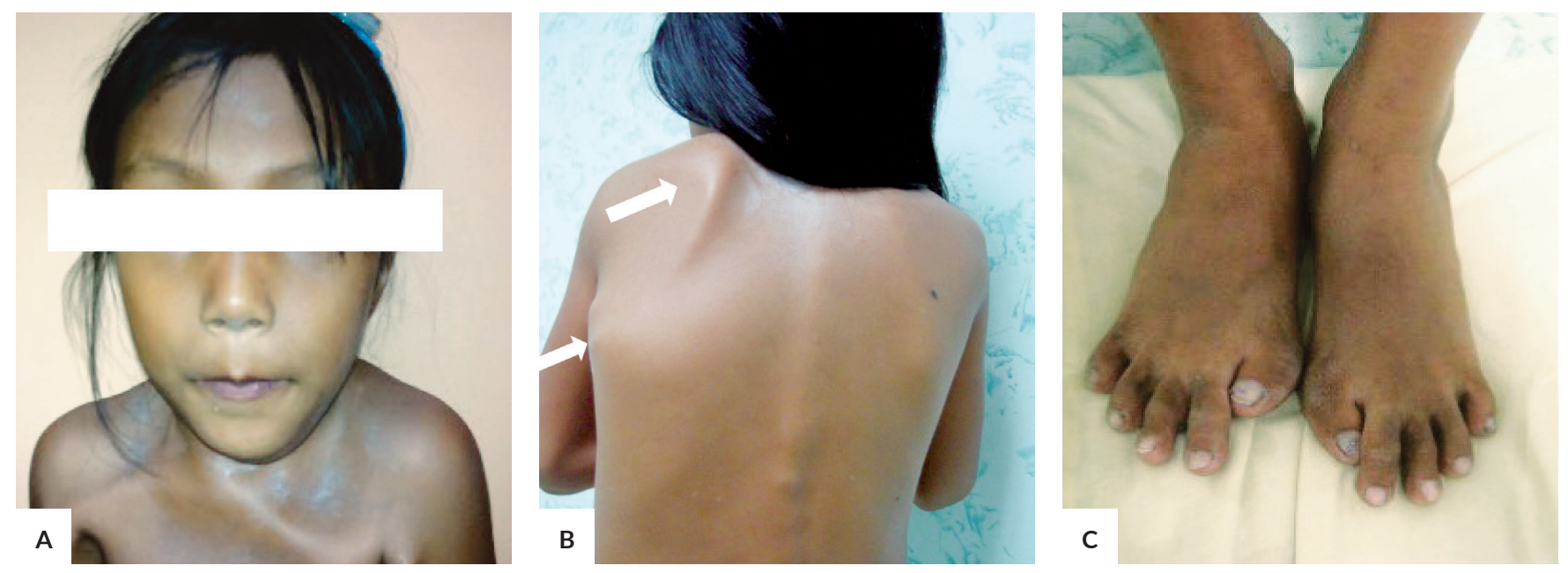

Figure 1. Patient 1. (A) Asymmetric clavicles with mass over sternum; (B) Klippel Feil deformity, arrows point to visible bumps over left scapula and ribs; (C) Medially deviated and shortened halluces. 


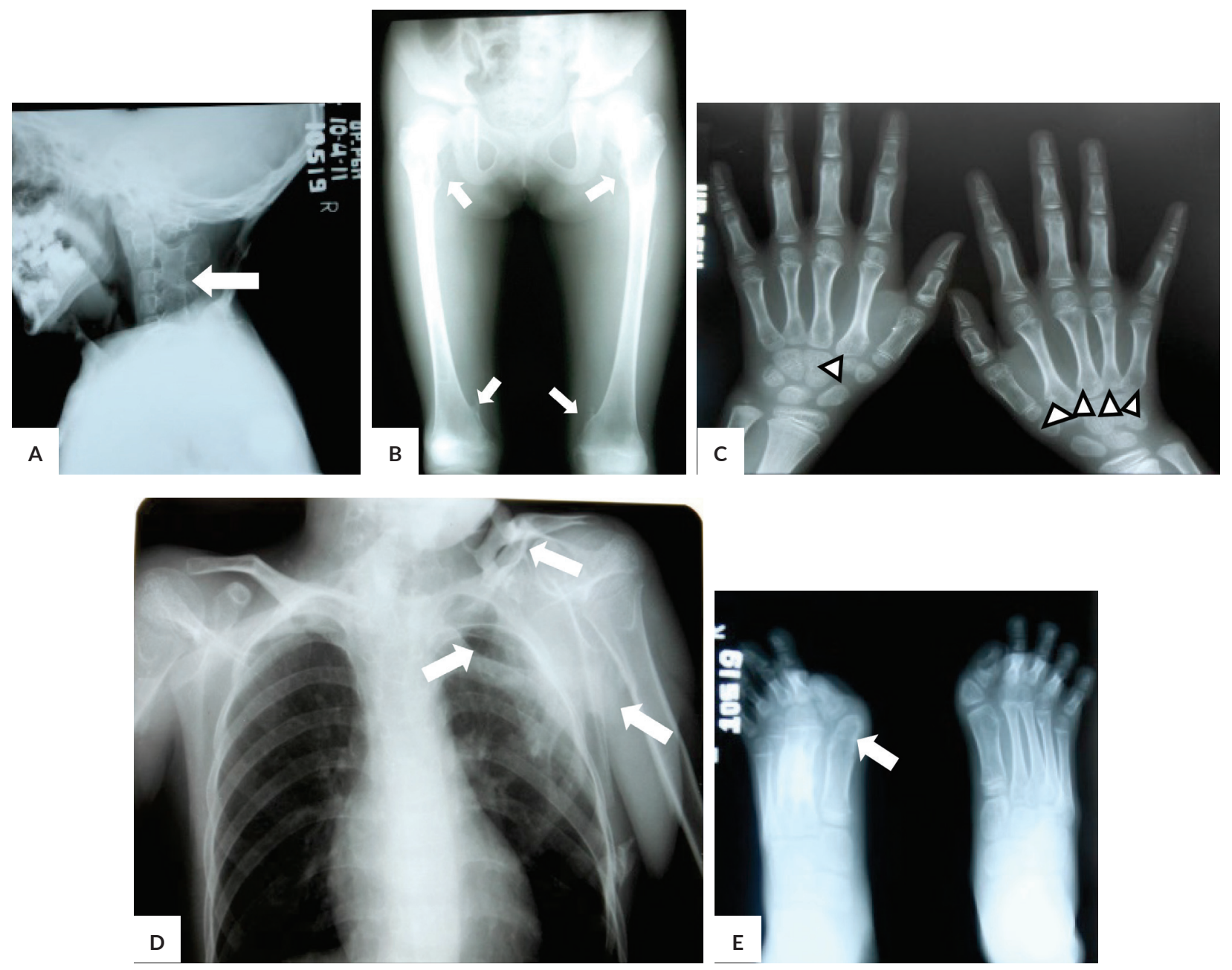

Figure 2. Patient 1. (A) Fusion of $\mathrm{C} 2-\mathrm{C} 3$ vertebral bodies and the posterior elements of $\mathrm{C} 2-\mathrm{C} 4$ and $\mathrm{C} 5-\mathrm{C} 7$; (B) Osteochondromas at the proximal and distal thirds of the femurs; (C) Osseous outgrowths at the proximal aspect of the right $2^{\text {nd }}-5^{\text {th }}$ and left $2^{\text {nd }}$ metacarpals (arrowheads); (D) Bony outgrowth from the sternal area spanning the left upper hemithorax extending to the supraclavicular area and assuming a somewhat triangular shape. Arrows outline the triangular shape; (E) Medially deviated and short halluces.

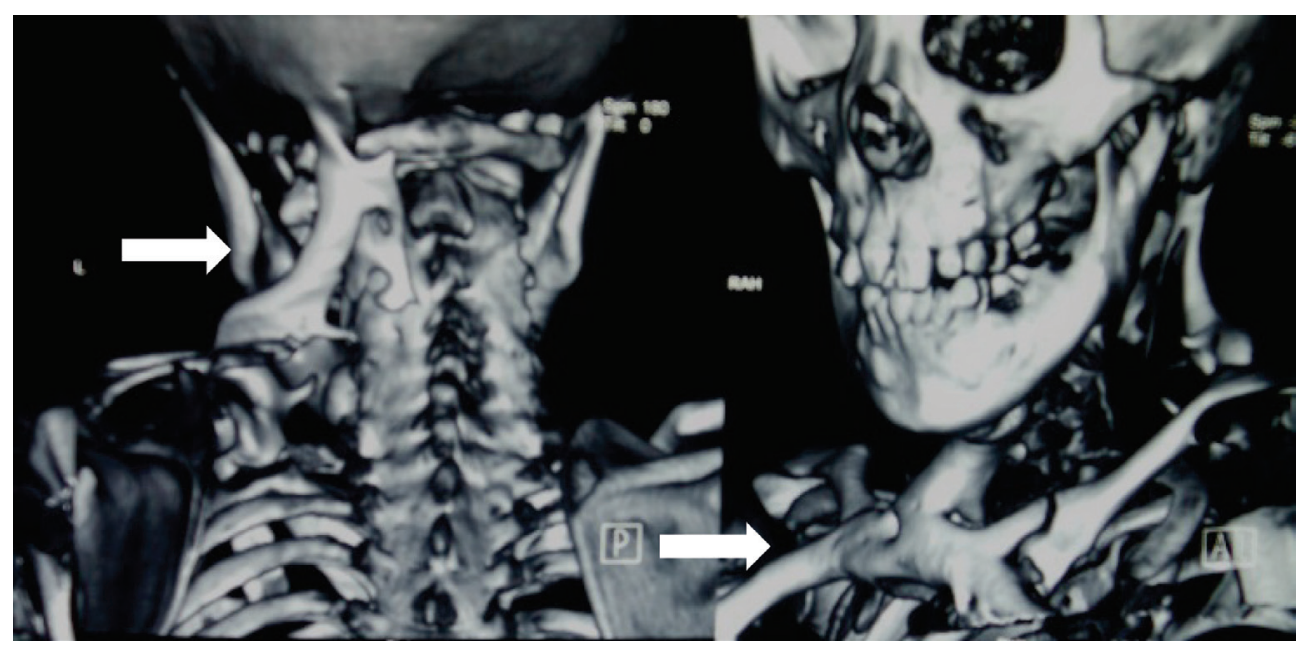

Figure 3. Patient 1. Computed tomography showing bony sheets at the neck and sternal areas (white arrows). 
Patient 2 was observed to have short great toes at birth but was otherwise well. A few days after birth, he developed a soft cranial mass at the right parieto-occipital area. The mass subsided but a hard lump remained. Radiographs of the skull at nine months of age were read as normal. No other symptoms were noted until he was six years of age when he developed jaw swelling and limited mouth opening. He was assessed to have a dental infection for which an antibiotic was prescribed. However, there was no resolution of the trismus although the swelling subsided after six months. At eight years of age, he developed right knee swelling which spontaneously resolved. Later, he had difficulty extending the right knee and began toe-walking. After a month, he developed a mass on the left calf and subsequently developed a fixed equinus deformity of both ankles. Persistence of the abnormal gait led to a consultation with a rheumatologist.

On physical examination, he had normal height and weight for age. He had palpable bony protuberances on the right parieto-occipital region, jaw, neck, knees and mid and lower back with asymmetry of the scapulae. He had limited movement of the temporomandibular joints allowing for less than two centimeters of mouth opening. He had ankylosis of the cervical spine and very limited range of motion of neck, shoulders, hips, knees and ankles. He stood and walked with hips and knees slightly flexed and feet in persistent plantar flexion. He had short, fixed, malformed great toes (Figure 4).
Patient 3 was healthy at birth but had short, deviated great toes similar to his brother's. There was no note of bumps or soft tissue masses until he was four years of age when he fell and subsequently developed a protuberance on the medial aspect of the right leg. He was brought for consultation and a radiograph right leg was done and interpreted as "abnormal bone growth." No further testing was performed.

At six years of age, he spontaneously developed a bony protuberance on the back without known trauma. Radiographs were obtained and interpreted as normal. There was no resolution of the bony protuberance. At eight years of age, he developed limited mouth opening, leading to difficulty eating solid foods. He also developed a right gluteal bony mass, without identified inciting event, making sitting difficult and at times painful. He was brought to the clinic, together with his brother, for subspecialist consultation.

On physical examination, he had normal height and weight for age. He had bony protuberances on the occipital region, medial aspect of the right leg, and most areas of the back with resulting scoliosis. He had hard masses at the right gluteal area. He had less than one centimeter of mouth opening. He also had limited range of motion of the neck, shoulders, hips and knees but had full range of motion of his ankles. He has short, laterally deviated, malformed great toes (Figure 4).

Patients 2 and 3 underwent skeletal surveys which showed multiple osteochondromas of the distal femurs and proximal tibias, bilateral hypoplastic, dyspastic great toes, short first metatarsals and extensive heterotopic ossification
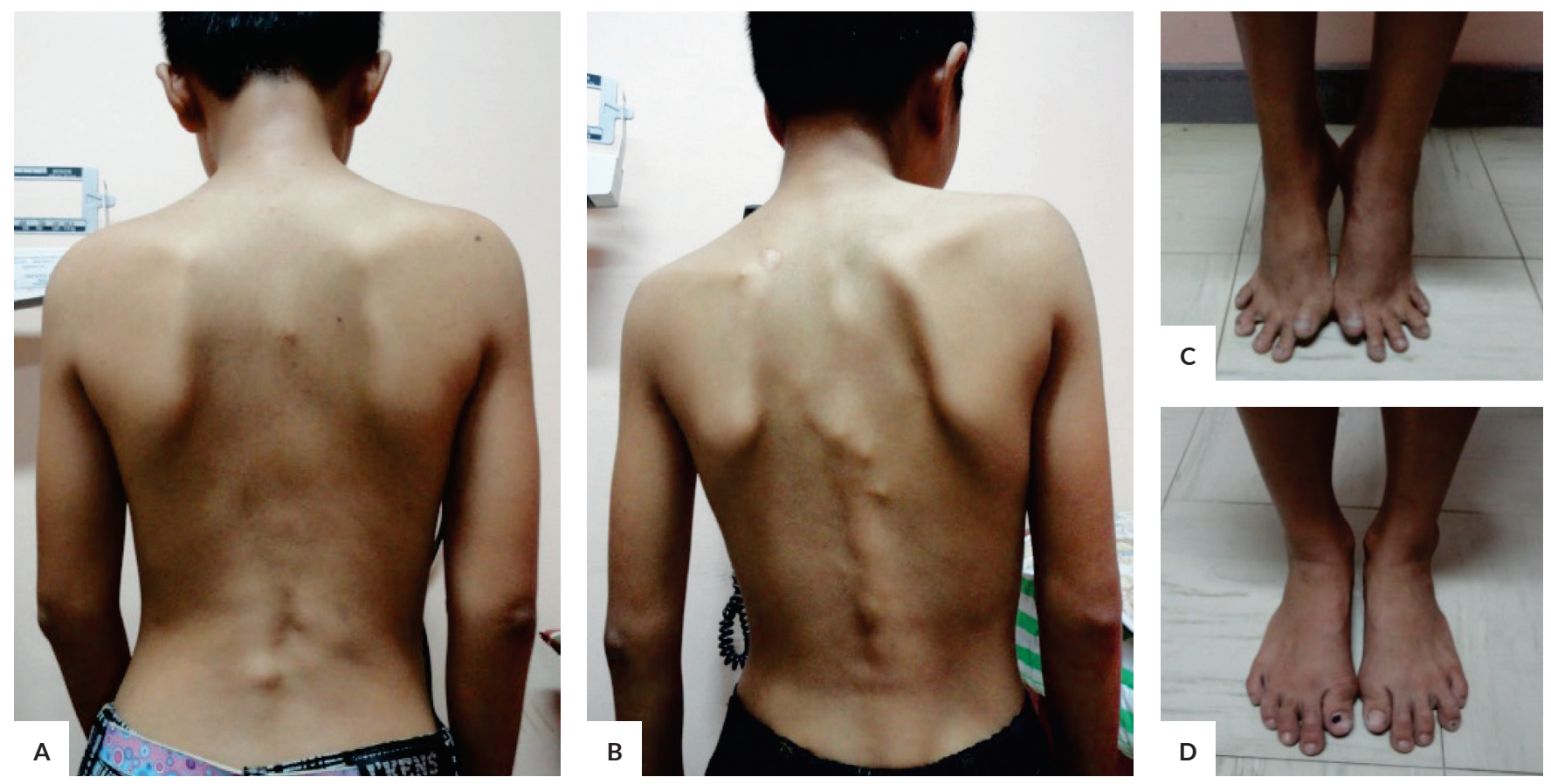

Figure 4. (A) Patient 2 back observed to have many bony protuberances; (B) Patient 3 back demonstrating bony protuberance of thoracic vertebrae with asymmetry of the scapulae; (C) Patient 2 feet showing persistent plantar flexion on standing, and bilaterally shortened halluces; (D) Patient 3 feet exhibiting the characteristic bilaterally short halluces. 
(Figure 5). Patient 2 had heterotopic ossification at the back of his right knee and left calf which explain the limited extension of knees and crouching gait. Patient 3 had a bony mass extending from the right femur to ischium.

The boys' parents were examined and were phenotypically unaffected. Mutation analyses were done after pre-test counseling and results showed that both brothers had the classic FOP mutation ACVR1/ALK2 c.617G>A; R206H while their parents did not have the mutation. Genetic counseling was provided for the family explaining that germline mosaicism was the most likely mechanism of affected siblings with unaffected parents.


Figure 5. (A) Patient 2. (B) Patient 3. White arrows point to multiple areas of ectopic bones. Note characteristic metaphyseal osteochondromas at the distal femur and medial aspect of proximal tibiae. Radiographs of feet of Patients 2 and 3 show short first metatarsals and bilateral hypoplastic dysplastic great toes. 


\section{DISCUSSION}

Here we report three Filipino children with similar presentations and clinical courses of classic FOP, characterized by great toe malformations and progressive post-natal heterotopic ossification. ${ }^{4}$ All had unremarkable prenatal and perinatal histories and were healthy with normal appearance at birth, apart from bilateral short malformed great toes. All three children were of normal intellect, and had similar histories of developing bony masses after minor physical trauma with the development of additional masses through time and resultant restricted joint movement. The restricted jaw movement caused feeding difficulties in all three children. Patient 1 had the common history among FOP patients of being advised surgery for removal of a bony mass. Surgery to remove the heterotopic bone in FOP is counterproductive and contraindicated and results in more aggressive episodes of ectopic bone formation. ${ }^{4}$ The characteristic radiographic findings of metaphyseal osteochondromas most typically found at the distal femora and medial aspect of proximal tibiae, ${ }^{9}$ as well as bilateral monophalangism of the great toes and short first metatarsals, were noted in all three children.

Molecular analysis revealed that all three children had the common ACVR1 mutation that has been found in patients with classic FOP. FOP in Patient 1 appears to be the result of a de novo (spontaneous) mutation, while FOP in the two brothers likely resulted from germline mosaicism for the ACVR1 mutation in a clinically unaffected parent. To our knowledge, these children are the first reported FOP patients in the Philippines, thus extending the range of classic FOP to new geographic and ethnic locations. With a population of approximately 100 million, and an estimated point prevalence of one in two million individuals, 50 patients with FOP are predicted in the country. Our report, although small, comprises approximately 6 percent of the estimated FOP population in the Philippines and provides the first glimpse of an FOP cohort in this region.

FOP is inherited in an autosomal dominant manner with complete penetrance. Reproductive fitness is low, and only a few multigenerational families have been identified worldwide. ${ }^{10-12}$ Most patients develop FOP as a result of a spontaneous new mutation as in the case of Patient 1. Germline mosaicism is the most plausible explanation for Patients 2 and 3, who both have the ACVR1 R206H mutation which is not detected in either of their unaffected parents. The possibility of germline mosaicism has also been suggested in a previous study that reported two affected siblings with unaffected parents but no genetic testing was available at that time. ${ }^{13}$ More recently, Pachoa et al. reported two African-American half-siblings with classic FOP features and mutation but no genetic testing was done on the unaffected mother and fathers. ${ }^{14}$ Thus, the family of Patients 2 and 3 is the first reported family with genetic testing done showing presence of the classical mutation in affected siblings not seen in the unaffected parents.
Occurrence of germline mosaicism would impact on recurrence risk assessment. In other autosomal dominant genetic disorders for which germline mosaicism has been established, recurrence risk for future pregnancies has been estimated at 5-6\%. ${ }^{15-16}$

Shore et al. ${ }^{17}$ have identified mutations in the gene coding activin A type I receptor (ACVR1) on chromosome 2q23-24 as the cause of this rare and severely disabling disease. ACVR1, which is expressed in most tissues of the body including skeletal, muscle and cartilage, helps regulate bone and muscle growth, normal skeletal maturation and ossification. ${ }^{18}$ In $98 \%$ of FOP cases, the heterozygous point mutation c. $617 \mathrm{G}>\mathrm{A}$ results in the substitution of arginine by histidine at codon 206 (p.R206H) within the glycine-serine activation domain of the receptor. ${ }^{17}$ Protein modeling predicted that this amino acid substitution results in conformational change of the receptor that alters its sensitivity and activity. ${ }^{19}$ In particular, this structure change may interrupt the normal process of binding of an inhibitor protein such as FKBP12 or may interfere with other mechanisms that control activation. Consequently, the receptor may be continuously activated (constitutive activation) leading to enhanced formation of bone and cartilage and joint fusion, resulting in the signs and symptoms of FOP. ${ }^{18}$

Kaplan et al. reported that among the 84 sporadic cases and seven families they have examined and clinically diagnosed with classic FOP, all affected individuals were heterozygous for the widely acknowledged (c.617G $>\mathrm{A}$; p.R206H) mutation in ACVR1. ${ }^{20}$

Atypical cases of FOP have also been recognized and described as two classes: FOP-plus (classic defining features of FOP plus one or more atypical features) and FOP variants (major variations in one or both of the two classic defining features of FOP) ${ }^{20}$ Atypical features occurring with FOP that have been reported in literature include nervous system, vision, developmental and hematologic findings. ${ }^{20-30}$ Most cases of FOP-plus had the classic c.617G>A; p.R206H mutation while two were found to have novel mutations (c.619C>G; p.Q207E and c.1067G>A; p.G356D). ${ }^{20}$ On the other hand, FOP variants were all found to have novel non- $\mathrm{R} 206 \mathrm{H}$ mutations in ACVR1. ${ }^{20}$

Extensive research is underway to fast-track the discovery of an effective drug that can prevent the formation of heterotopic ossification. There are three promising drugs that are currently being studied-each aiming to target different mechanisms in heterotopic ossification. Palovarotene, a retinoic acid receptor agonist, has been proven in animal studies to inhibit chondrogenesis and can prevent both trauma-induced and spontaneous heterotopic ossification. ${ }^{31}$ Another drug, garetosmab, acts as an antibody that blocks Activin A, which may aberrantly act via mutant ACVR1 to transduce osteogenic signals and trigger heterotopic bone formation. ${ }^{32} \mathrm{~A}$ third drug, at the early stages of development, is a mutation-allele specific 
Fibrodysplasia Ossificans Progressiva in Three Filipino Children

inhibitory RNA that can suppress the expression of mutated ACVR1 gene. ${ }^{33}$

Currently, treatment remains symptomatic. Corticosteroids are generally restricted to extremely early symptomatic treatment of flare-ups that affect major joints, jaw and the submandibular area. These are also used in the prevention of flare-ups in emergent, elective, and minor surgeries such as dental surgery, hypospadias repair, appendectomies, peri-operative use, and in the prevention of flare-ups following major soft tissue injury (severe trauma). Selective cyclo-oxygenase-2 (cox-2) inhibitors and non-steroidal anti-inflammatory drugs (NSAIDs) can be given as symptomatic treatment for pain and swelling. ${ }^{11}$ For our three children, four-day course of prednisone was prescribed for flare-ups.

\section{CONCLUSION}

FOP is a severely debilitating disease that needs early recognition and appropriate management. Physicians, health care professionals, and more importantly patients and their families must be properly educated about the condition. Bringing critical awareness to the Filipino medical community is important so that prompt and correct clinical diagnosis can be done. Furthermore, diagnostic delays and unnecessary possibly harmful procedures might be avoided for the remaining FOP patients in the Philippines yet to be discovered. Although medications are available to help alleviate symptoms, the best current approach is still early diagnosis and prevention of trauma that can lead to development of masses and the consequent disabilities.

In this case series, we presented three Filipino children with FOP. This further supports previous reports that FOP has no racial, ethnic, gender or geographic predilection. Additionally, we present the occurrence of FOP in two siblings with phenotypically and genotypically unaffected parents. This is the first reported family after the discovery of the causative gene, ACVR1, with these genetic results. This further supports the occurrence of germline mosaicism in this condition-an observation that impacts the recurrence risk assessment for future pregnancies in a family with siblings affected with FOP.

\section{Ethical Consideration}

Written informed consent for the three children were secured for publication.

\section{Acknowledgment}

Dr. Melissa Baluyot was a research associate at the Institute of Human Genetics when the manuscript was initially started and contributed significantly in the gathering of clinical data.

\section{Statement of Authorship}

All authors have approved the final version submitted.

\section{Author Disclosure}

All authors declared no conflicts of interest.

\section{Funding Source}

None.

\section{REFERENCES}

1. Kaplan FS, Pignolo RJ (eds), and The International Clinical Consortium on FOP. The medical management of fibrodysplasia ossificans progressiva: current treatment considerations. Proc Intl Clin Council FOP. 2019; 1:1-111.

2. Cohen RB, Hahn GV, Tabas JA, Peeper J, Levitz CL, Sando A, et al. The natural history of heterotopic ossification in patients who have fibrodysplasia ossificans progressiva. J Bone Joint Surg Am. 1993 Feb; 75(2):215-9.

3. FOP Fact Sheet [Internet]. [cited 2017 Feb 2]. Available from: http://www.ifopa.org/en/fop-fact-sheet.html.

4. Kaplan FS, LeMerrer M, Glaser DL, Pignolo RJ, Goldsby RE, Kitterman JA, et al. Fibrodysplasia ossificans progressiva. Best Pract Res Clin Rheumatol. 2008 Mar; 22(1):191-205.

5. Pignolo RJ, Shore EM, Kaplan FS. Fibrodysplasia ossificans progressiva: clinical and genetic aspects. Orphanet J Rare Dis. 2011 Dec; 6:80.

6. Kaplan F, Xu M, Glaser D, Collins F, Connor M, Kitterman J et al. Early diagnosis of fibrodysplasia ossificans progressiva. Pediatrics. 2008 May; 121(5): e1295-300.

7. Kitterman JA, Kantanie S, Rocke DM, Kaplan FS. Iatrogenic harm caused by diagnostic errors in fibrodysplasia ossificans progressiva. Pediatrics 2005 Nov; 116(5):e654-61.

8. Nucci A, Queiroz LS, Santos AD, Camargo EE, Moura-Ribeiro MV. Fibrodysplasia ossificans progressiva case report. Arq Neuropsiquiatr 2000 Jun; 58(2A):342-7.

9. Deirmengian GK, Hebela, NM, O'Connell M, Glaser DL, Shore EM, Kaplan FS. Proximal tibial osteochondromas in patients with fibrodysplasia ossificans progressiva. J Bone Joint Surg. 2008 Feb; 90(2):366-74.

10. Shore EM, Feldman GJ, Xu M, Kaplan FS. The genetics of fibrodysplasia ossificans progressiva. Clin Rev Bone Miner Metab. 2005; 3(3-4):201-4.

11. Kaplan FS, McCluskey W, Hahn G, Tabas JA, Muenke M, Zasloff MA. Genetic transmission of fibrodysplasia ossificans progressiva. J Bone Joint Surg Am. 1993 Aug; 75(8):1214-20.

12. Connor JM, Skirton H, Lunt PW. A three generation family with fibrodysplasia ossificans progressiva. J Med Genet. 1993 Aug; 30(8):687-9.

13. Janoff HB, Muenke M, Johnson LO, Rosenberg A, Shore EM, Okereke E, et al. Fibrodysplasia ossificans progressiva in two halfsisters: evidence for maternal mosaicism. Am J Med Genet. 1996 Feb; 61(4):320-4.

14. Pachajoa H, Ramirez Botero AF. Clinical and molecular characterisation of two siblings with fibrodysplasia ossificans progressiva, from the Colombian Pacific coast (South America). BMJ Case Rep. 2015 Jun; 2015:bcr2015209804. doi:10.1136/bcr-2015209804.

15. Byers PH, Tsipouras P, Bonadio JF, Starman BJ, Schwartz RC. Perinatal lethal osteogenesis imperfecta (OI type II): A biochemically heterogenous disorder usually due to new mutations in the genes for type I collagen. Am J Hum Genet. 1988 Feb; 42(2):237-48.

16. Hall JG. The clinical behavior of hereditary syndromes with a precis of medical genetics. In: Beighton P, ed. McKusick's Heritable Disorders of Connective Tissue. St Louis: C.V. Mosby Co.; 1993. pp. 1-32.

17. Shore EM, Xu MQ, Feldman GJ, Fenstermacher DA, Cho TJ, Choi $\mathrm{IH}$, et al. A recurrent mutation in the BMP type I receptor ACVR1 causes inherited and sporadic fibrodysplasia ossificans progressiva. Nat Genet. 2006 May; 38(5):525-7. 
18. ACVR1. Genetics Home Reference. US National Library of Medicine [Internet]. 2012. [cited 112012 Feb] Available from: http://ghr.nlm. nih.gov/gene=ACVR1

19. Groppe JC, Shore EM, Kaplan FS. Functional Modeling of the ACVR1 (R206H) mutation in FOP. Clin Orthop Relat Res. 2007 Sep; 462:87-92.

20. Kaplan FS, Xu M, Seemann P, Connor M, Glaser DL, Carroll L, et al. Classic and atypical Fibrodysplasia Ossificans Progressiva (FOP) phenotypes are caused by mutations in the Bone Morphogenetic Protein (BMP) Type 1 Receptor ACVR1. Hum Mutat. 2009 Mar; 30(3):379-90.

21. Kaplan FS, Glaser DL, Shore EM, Pignolo RJ, Xu M, Zhang Y, et al. Hematopoietic stem-cell contribution to ectopic skeletogenesis. J Bone Joint Surg Am. 2007 Feb; 89(2):347-57.

22. Frame B, Azad N, Reynolds WA, Saeed SM. Polyostotic fibrous dysplasia and myositis ossificans progressiva. A report of coexistence. Am J Dis Child. 1972 Jul; 124(1):120-2.

23. Davis SW, Camper SA. Noggin regulates Bmp4 activity during pituitary induction. Dev Biol. 2007 May; 305(1):145-60.

24. Angley C, Kumar M, Dinsio KJ, Hall AK, Siegel RE. Signaling by bone morphogenetic proteins and Smad1 modulates the postnatal differentiation of cerebellar cells. J Neurosci. 2003 Jan; 23(1):260-8.

25. Andreev K, Zenkel M, Kruse F, Junemann A, Schlotzer-Schrehardt U. Expression of bone morphogenetic proteins (BMPs), their receptors, and activins in normal and scarred conjunctiva: role of BMP-6 and activin-A in conjunctival scarring? Exp Eye Res. 2006 Nov; 83(5):1162-70.
26. Wordinger RJ, Clark AF. Bone morphogenetic proteins and their receptors in the eye. Exp Biol Med. 2007 Sep; 232(8):979-92.

27. Wordinger RJ, Fleenor DL, Hellberg PE, Pang IH, Tovar TO, Zode GS, et al. Effects of TGF-beta2, BMP-4, and gremlin in the trabecular meshwork: implications for glaucoma. Invest Opthalmol Vis Sci. 2007 Mar; 48(3):1191-200.

28. Knight PG, Glister C. TGF-beta superfamily members and ovarian follicle development. Reproduction. 2006 Aug; 132(2):191-206.

29. Lee NK, Sowa H, Hinoi E, Ferron M, Ahn JD, Confavreux C, et al. Endocrine regulation of energy metabolism by the skeleton. Cell. 2007 Aug; 130(3):456-69.

30. Thesleff I. The genetic basis of tooth development and dental defects. Am J Med Genet A. 2006 Dec; 140(23):2530-5.

31. Chakkalakal SA, Uchibe K, Convente MR, Zhang D, Economides AN, Kaplan FS, et al. Palovarotene inhibits heterotopic ossification and maintains limb mobility and growth in mice with the human ACVR1R206H Fibrodysplasia Ossificans Progressiva (FOP) mutation. J Bone Miner Res. 2016 Sep; 31(9):1666-75.

32. Allesi Wolken DM, Idone V, Hatsell SJ, Yu PB, Economides AN. The obligatory role of Activin A in the formation of heterotopic bone in Fibrodysplasia Ossificans Progressiva. Bone. 2018 Apr; 109:210-7.

33. Kaplan FS, Pignolo RJ, Al Mukaddam MM, Shore EM. Hard targets for a second skeleton: therapeutic horizons for fibrodysplasia ossificans progressiva (FOP). Expert Opin Orphan Drugs. 2017; 5(4):291-4.

Have you read the current trends in Medical and Health Research in the Philippines?

\title{
Acta Medica Philippina The National Health Science Journal
}

\author{
Access Online: www.actamedicaphilippina.upm.edu.ph
}

